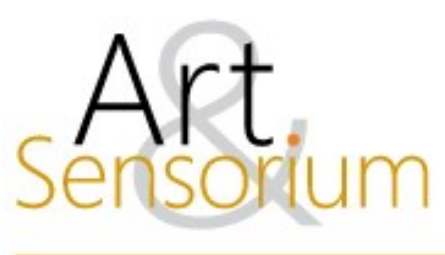

\title{
A ARTE CONCEITUAL E A CONTRIBUIÇÃO DE GUILHERME VAZ (1969-1975)
}

\author{
https://doi.org/10.33871/23580437.2021.8.1.048-060
}

Tamara Silva Chagas ${ }^{1}$

\begin{abstract}
Resumo: A arte conceitual é uma vertente desmaterializada que retira a ênfase da obra-objeto para realocá-la na ideia ou na ação. Sua versão histórica teve seu apogeu de meados da década de 1960 até o final dos anos 1970, quando começou a ser suplantada como tendência predominante no circuito nacional e internacional pelo retorno à pintura. No entanto, sua estrondosa influência permanece até os dias de hoje. O presente estudo de caso, que adota as metodologias qualitativa e explicativa, pretende refletir sobre a arte conceitual como fenômeno internacional e destacar a contribuição dada ao debate pela produção brasileira, salientando especialmente algumas obras do artista Guilherme Vaz, elaboradas entre 1969 e 1975. Para fins desta pesquisa, recorrer-se-á como referencial teórico a textos seminais sobre o tema de autoria de Joseph Kosuth, Sol LeWitt, Mari Carmen Ramírez e Cristina Freire.
\end{abstract}

Palavras-chave: Guilherme Vaz; arte conceitual; desmaterialização.

\section{Conceptual Art and Guilherme Vaz's Contribution (1969-1975)}

Abstract: Conceptual art is a dematerialized art, which removes the emphasis from the object to reallocate it in the idea or in the action. Its historical version had its apex from de mid-1960s until the end of the 1970s, when it began to be supplanted as a predominant trend in the national and international circuit by the return to painting. However, its resounding influence remains nowadays. This case study, which adopts qualitative and explanatory methodologies, intends to reflect on conceptual art as an international phenomenon and to highlight the Brazilian contribution to the debate, especially highlighting some works created by the artist Guilherme Vaz, elaborated between 1969 and 1975. For the purposes of this research, it will be used, as a theoretical reference, seminals texts on the topic, written by Joseph Kosuth, Sol LeWitt, Mari Carmen Ramírez and Cristina Freire.

Keywords: Guilherme Vaz; Conceptual Art; dematerialization.

\section{El Arte Conceptual y la Contribuición de Guilherme Vaz (1969-1975)}

Resumen: El arte conceptual es un tipo de arte desmaterializado, que quita el énfasis de la obra para reasignarlo en la idea o en la acción. Su versión histórica alcanzó su auge desde mediados de los años sesenta hasta finales de los setenta, cuando comenzó a ser superada como tendencia predominante en el circuito nacional e internacional por el regreso a la pintura. Sin embargo, su contundente influencia permanece hoy. El presente estudio de caso, que adopta las metodologías cualitativa y explicativa,

\footnotetext{
${ }^{1}$ Doutoranda em História pelo PPGHis da Universidade Federal do Espírito Santo, sob orientação da Profa. Dra. Almerinda da Silva Lopes. Mestre em Artes (UFES, 2012). Bacharel em Artes Plásticas (UFES, 2008). Graduada em Gestão de Recursos Humanos (UVV, 2019). Bolsista CAPES. Autora do livro "Frederico Morais: a crítica de arte e seus desdobramentos", publicado pela Edufes, em 2019. (https://orcid.org/0000-0002-9378-3969). tamara.chagas@edu.ufes.br
} 
pretende reflexionar sobre el arte conceptual como fenómeno internacional y resaltar la contribución al debate de la producción brasileña, destacando especialmente algunas obras del artista Guilherme Vaz, elaboradas entre 1969 y 1975. Para los propósitos de esta investigación, se utilizarán como marco teórico textos seminales sobre el tema de Joseph Kosuth, Sol LeWitt, Mari Carmen Ramírez y Cristina Freire.

Palabras clave: Guilherme Vaz; arte conceptual; desmaterialización.

\section{Considerações iniciais}

Com a mudança do eixo do circuito artístico de Paris para Nova York, após a Segunda-Guerra Mundial, muitas mudanças ocorreram. A princípio, surgiu e se solidificou uma vertente da arte moderna particularmente estadunidense: o expressionismo abstrato, que abrangia os fenômenos estéticos da action painting e da color field painting. A primeira tratava-se de uma pintura de características gestuais, algumas vezes performáticas, com alto grau de aleatoriedade e subjetividade. A segunda, por sua vez, era também gestual e subjetiva, porém englobava pinturas de grandes campos de cor com aspirações muitas vezes transcendentais. O expressionismo abstrato tinha como grande defensor e legitimador o crítico de arte Clement Greenberg, de inclinação neokantiana, que pregava o formalismo e a autonomia da arte diante das outras áreas. Greenberg advogava em prol da pureza artística: para o crítico, cada linguagem deveria se restringir aos seus elementos específicos, evitando a "contaminação" por componentes de outros tipos de arte (GREENBERG, 2001, p. 53). Por exemplo, a pintura deveria se ater à sua planaridade e evitar a literalidade, característica da escultura, ou a narração, atrelada à literatura.

Esse era o tipo de arte predominante no circuito artístico quando da chegada de duas figuras que iriam influenciar a arte da década de 1960: Jasper Johns e Robert Rauschenberg. Nos anos 1950, esses neodadaístas se tornaram importantes pelo resgate de noções duchampianas, tal como o readymade. $\mathrm{O}$ readymade é um objeto do cotidiano fabricado pela indústria, escolhido pelo artista e imerso no interior do sistema da arte. O exemplo mais notório de readymade é Fonte, de Marcel Duchamp, um urinol comprado pelo artista e assinado "R. Mutt". Este foi inscrito na exposição da Associação de Artistas Independentes de Nova York, em 1917, causando muita polêmica.

Esse resgate do readymade se desdobraria nas tendências que floresceram nos anos 1960, como a pop art, a op art, a arte cinética, o minimalismo, o happening - tão caro ao grupo Fluxus -, a body art, a land art e a arte conceitual. A tendência progressiva à desmaterialização da obra conecta todas essas tendências, sendo radicalizada especialmente pela vertente da arte conceitual. $O$ termo "desmaterialização" foi cunhado pelos críticos Lucy Lippard e John Chandler em breve ensaio escrito em 1967 e publicado no ano seguinte, na revista Art International (LIPPARD; CHANDLER, 1999, p. 46-50 passim). Nele os críticos constatam a ultrapassagem da "arte ultra-conceitual" sobre as tendências intuitivas no período anterior (anos 1940 e 1950), realocando a ênfase da emoção e da visualidade para o pensamento. O objeto artístico tornara-se obsoleto em face da ascensão da arte como ideia (LIPPARD; CHANDLER, 1999, p. 46). Destarte, a arte deixaria de representar o mundo interior do artista para se tornar um conceito a ser comunicado. A arte ultra-conceitual, observada por Lippard e Chandler, dar-se-ia em duas direções, a saber, a arte como ideia e como ação.

De fato, as tendências acima citadas representaram uma descontinuidade em relação à arte moderna. Inauguraram um novo momento para a arte, a chamada arte contemporânea. O subjetivismo, a autonomia artística, o formalismo e a busca pela pureza alcançada na especificidade dos meios de cada linguagem, questões estas que permearam o expressionismo abstrato, visto por Greenberg como o clímax da arte moderna, deixaram ser relevantes para a nova arte, que expressava uma visão de mundo original (FERREIRA; COTRIM, 2001, p. 14). Alguns, como Mário Pedrosa, um dos mais 
importantes críticos do Brasil, chamaria a produção artística surgida a partir do advento da pop de "pós-moderna", pois via nascer com ela um novo ciclo da arte, agora ancorada por novos parâmetros (PEDROSA, 2006, p. 143). Essa discussão é profícua, entretanto, não se aprofundará nela para não retirar o foco do tema central deste estudo. Vale salientar, entretanto, que a arte pós-moderna é marcada pelo retorno ao real e pelo fim das narrativas totalizantes e evolucionistas segundo Danto (2006), como a própria narrativa crítica produzida por Clement Greenberg, que via na arte uma trajetória evolutiva rumo à pureza, culminando com o expressionismo abstrato.

Em Six Years, livro de Lucy Lippard, parte da produção conceitual de 1966 a 1972 é catalogada. Nele, a crítica situa a arte conceitual no mesmo contexto histórico marcado pela luta pelos direitos civis, o protesto contra a Guerra do Vietnã, o movimento de liberação feminina e a contracultura (LIPPARD, 2001, p. VII). Essa contextualização é importante, pois permite compreender a arte conceitual como um fenômeno histórico caracterizado pela busca de novos parâmetros diante de uma realidade diversa inaugurada com o Pós-Guerra, assim como boa parte dos movimentos da época, os quais procuravam por mudanças políticas, sociais e culturais que atendessem às suas expectativas de um mundo melhor, mais justo, igualitário e inclusivo. A arte conceitual está em consonância com esse esforço, visto que, como se verá adiante, ela buscou em muitos casos a democratização da arte e a superação da ideia de obra como mercadoria.

Nesta pesquisa, refletir-se-á sobre o que é a arte conceitual e, a partir dessa discussão, debater-se-á algumas obras de Guilherme Vaz, artista conceitual de grande relevância para a arte brasileira do final dos anos 1960 e início da década de 1970. Todavia, vale salientar a extrema escassez de pesquisas sobre sua obra, o que o relegou ao esquecimento durante muito tempo. Nesse sentido, é preciso destacar, como relevante material que serviu de base para o levantamento de dados sobre o artista e sua obra, o livro-catálogo Guilherme Vaz: uma fração do infinito (MANATA, 2016), publicado em ocasião da exposição retrospectiva homônima, realizada no Centro Cultural Banco do Brasil do Rio de Janeiro, em 2016, sob curadoria de Franz Manata.

\section{Arte conceitual: ortodoxia versus heterodoxia}

O termo arte conceitual foi cunhado por Henry Flynt, em 1961 (BUCHLOH, 1999, p. 515). Ele seria usado posteriormente, em meados dos anos 1960, para agrupar uma série de trabalhos ligados por seu realce na ideia e/ou ação. Além disso, os artistas ligados a essa corrente romperam com o limite entre as linguagens em prol de uma criação intermídia, na qual poderiam se misturar elementos das artes visuais, do teatro, da literatura, da música, do cinema, etc. Com isso, decretava-se o fim das categoriais artísticas tradicionais, como pintura e escultura. Nesse sentido, foram propostas obras como Manifesto contra o júri, de Artur Barrio, um texto no qual o artista se opunha contra o júri do II Salão de Verão, de 1970, por este ter aceitado um de seus manifestos, escrito à mão e repetido três vezes, na categoria "Desenho". Para o artista, por trás daquela atitude havia o esforço em retirar do trabalho seu potencial contestatório, pois seu aceite deveria, por consequência, implicar na recusa de todas as demais obras, as quais foram inscritas em categorias (BARRIO, 2002b, p. 148-149 passim).

Entre os artistas mais comumente relacionados à arte conceitual estão, entre muitos outros, Joseph Kosuth, Sol LeWitt (às vezes também classificado como minimalista), On Kawara, Christine Kozlov e o grupo Art\&Language, formado no Reino Unido, em 1967, pelos artistas Michael Baldwin, Terry Atkinson, David Bainbridge e Harold Hurrel, que juntos lançaram a revista Art-Language, importante divulgadora das ideias dos conceitualistas. O coletivo britânico questionava a pura visualidade da arte e se voltava para a pesquisa com o uso da palavra escrita para expressar uma ideia (ART\&LANGUAGE, 2006, p. 236-237 passim). É interessante notar que boa parte da obra de Sol LeWitt é composta por pinturas murais. Contudo, sua pintura precisa ser vista como algo desconectado da tradição desta categoria, embora a comente. Segundo o artista, a obra para a arte conceitual é ideia e, dessa forma, não precisa ter uma realidade física necessariamente (LEWITT, 
2006b, p. 206). Nesse sentido, talvez se possa dizer que suas pinturas não são pinturas, mas ideias sobre a pintura: um discurso sobre essa linguagem que retira a ênfase do processo de percepção visual do espectador para instigar seu intelecto, levando-o a se questionar sobre a natureza da arte.

A arte conceitual se trata, assim, de uma vertente que problematiza a definição de arte, numa crítica ao objeto artístico como mercadoria e às instituições que o legitimam (FREIRE, 2006, p. 8). De acordo com Freire (2006), é importante diferenciá-la do conceitualismo, pois a primeira é um fenômeno histórico com duração determinada e a última é uma tendência à desmaterialização que, pensa-se, pode ser descrita como decorrente do impacto da primeira sobre a posteridade. Paul Wood também alerta para a diferença entre o termo arte conceitual e conceitualismo: enquanto o primeiro designa uma forma histórica de vanguarda, o segundo é uma expressão geral que abarca uma diversidade de práticas inseridas na contemporaneidade que divergem da arte como tradicionalmente é vista nas exposições convencionais (WOOD, 2002, p. 9).

De acordo com Joseph Kosuth, a arte deve ser uma proposta analítica que comente a si própria, apresentando-se como uma proposição a respeito da definição de seu conceito (KOSUTH, 2006, p. 219-220 passim). Esse aspecto tautológico permeou boa parte da produção conceitualista anglo-saxã. Contudo, a ortodoxia pregada por Kosuth não conseguiu abarcar a produção de alguns artistas que romperam com a tautologia e se interessaram pela realidade social e política circundante, como Hans Haacke e diversos artistas latino-americanos, como se verá mais à frente.

Já Sol LeWitt redefine a função do artista, que deixa de ser artesão para se tornar um planejador cujo objetivo é fazer da obra algo "mentalmente interessante" e "emocionalmente seco" (LEWITT, 2006a, p. 177). Segundo o artista, a obra conceitual não precisa ser lógica ou complexa: muitas das melhores ideias são simples (LEWITT, 2006a, p. 177). Destarte, a arte conceitual não se trata de um comentário sobre uma corrente filosófica. Ao contrário, sua filosofia é implícita ao trabalho e não externa (LEWITT, 2006a, p. 179). Apesar de não ser ilustração sobre uma teoria filosófica, esse tipo de arte se aproxima bastante da filosofia, mesmo sendo um tipo intuitivo de criação. Fala-se isso em contraposição à ideia de LeWitt, para quem a produção conceitual nada tem em comum com a Filosofia ou a Matemática. Isso porque a arte, nessa tendência, se transforma em pensamento reflexivo, a princípio, sobre a própria instituição arte e, depois, como se verá, sobre a realidade social e política de sua conjuntura.

Para Mari Carmen Ramírez (2007, p. 185), a arte conceitual se contrapõe à fetichização da obra, transformada em mercadoria, e ao sistema artístico, que legitima essa mercantilização. A artesania é relegada em prol do pensamento. $\mathrm{O}$ aspecto estético, como sinônimo de belo, deixa de ter relevância no contexto da arte conceitual, já que a obra não necessita mais ter apelo visual, sendo o aspecto mental o polo de interesse do artista (LEWITT, 2006a, p. 178).

Exemplo emblemático de arte conceitual tal como pregava Kosuth, ou seja, dentro da ortodoxia definia no texto A arte depois da filosofia, publicado na revista Studio International em três partes, em 1969, é a obra Uma e três cadeiras, do mesmo artista. Kosuth justapôs uma cadeira, uma fotografia de cadeira e a definição da palavra "cadeira" retirada de um dicionário. Segundo Archer, o artista criou com sua obra um jogo entre realidade, ideia e representação, inspirando-se para isso na filosofia de Ludwig Wittgenstein, especialmente no estudo da linguagem como forma de representação (ARCHER, 2008, p. 82). Outras obras do período do mesmo artista consistiam em fotocópias de definições de palavras. Também são notórias as obras do japonês On Kawara em forma de telegrama enviado para diversas pessoas com a frase "Eu ainda estou vivo" e suas pinturas de datas, que ele realizou desde 1966 até o ano de seu falecimento, em 2014, como Nov. 26, 1966, número 217 da chamada Today Series. Ao pintar datas, On Kawara retira da pintura todo o caráter emocional e subjetivo a ela atrelada. O artista substitui a emoção, assunto principal da pintura do expressionismo abstrato, pela frieza da informação sem apelo à sensibilidade do espectador. Por outro lado, a obra pode ser vista como uma tentativa, sabidamente frustrada, de captar o tempo, efêmero por natureza. 
Artistas como os acima citados, mais alinhados à noção mais ortodoxa da arte conceitual, diferentemente dos conceitualistas heterodoxos - que recorriam a materiais diversos para sua obra, embora sempre os deixando em segundo plano em razão da ideia ou da ação -, trouxeram a linguagem como material das artes visuais, aproximando-se da poesia experimental. Também vale salientar a fusão das artes visuais com outras artes, para além da literatura: como o exemplo do teatro, como se pode ver na profusão de happenings e performances propostos por artistas contemporâneos a partir de 1960; e a música, da qual o grande expoente influenciador da arte a partir daquele decênio foi John Cage, que propôs obras como a icônica 4'33',' de 1952, em que o músico fica em silêncio, sem nada tocar, pelo tempo estipulado no título. O trabalho em si, além do silêncio do músico, engloba o barulho feito pela plateia inquieta, que tosse e respira durante a execução dessa antipeça. Guilherme Vaz, que será abordado mais à frente, também ele músico e artista conceitual, misturou ambas as linguagens artísticas para criar uma poética original, escrevendo palavras como "silêncio" em papel com pauta destinado à notação musical, além de outros projetos de obras, para os quais também fez uso de anotações sobre o mesmo tipo de papel, articulando música, linguagem e performance.

Frederico Morais, um dos mais importantes críticos brasileiros, destacou três exposições como eventos impulsionadores da nascente tendência conceitual. Estas são Live in your head: when attitudes become form, relizada na Kunsthalle de Berna, Suíça, em 1969, com curadoria de Harald Szeemann; Konzeption/Conception, ocorrida no Museu Städtischen, em Leverkusen, Alemanha, no final de 1969, com curadoria de Konrad Fisher e Rolf Wedewer; e Information: summer 70, realizada no Museu de Arte Moderna de Nova York (MoMA), em 1970, organizada por Kynaston McShine (MORAIS, 2007). As mostras congregavam mais que obras no sentido tradicional da palavra - vistas como entidade única, acabada, aurática e fechada à participação, quase uma relíquia digna de devoção e culto -, mas sim processos, informações, documentos e situações. Diante disso, é digna de nota a existência, por exemplo, do catálogo de Information como um fenômeno paralelo, porém não submisso à condição de mero registro da exposição. Os artistas foram convidados pelo curador da mostra, também editor do catálogo, a elaborar algo para publicação no livro, podendo estar relacionado ou não ao trabalho exposto no MoMA (INFORMATION, 1970, p. 138). Houve até mesmo o notório caso da exposição The Xerox Book, cuja curadoria foi feita pelo marchand Seth Siegelaub, ocorrida apenas sob a forma de catálogo, publicado em 1969. Para a "exposição" os artistas Joseph Kosuth, Sol LeWitt, Robert Morris, Lawrence Weiner, Robert Morris, Carl Andre e Douglas Huebler foram convidados a elaborar propostas a partir da fotocópia, dispondo cada um de 25 páginas do livro (FREIRE, 2006, p. 57).

Muitas das "obras" expostas nessas mostras se constituíam de projetos a serem ou não realizados no futuro, ou documentação de trabalhos já realizados em outros locais, o que deslocou a temporalidade da existência da obra do momento de sua recepção. A natureza desmaterializada desse tipo de produção trouxe aos artistas a necessidade de se recorrer a formas de registro, como a fotografia, o filme Super 8 e o vídeo, que foi introduzido no mercado naquele momento. Essa documentação, que também era composta por textos escritos, projetos, mapas, esquemas e todo o tipo de informação sobre o trabalho proposto, era, na maioria das vezes, o que iria ser exposto na instituição museológica. Isso reforça o deslocamento do interesse do objeto e de sua materialidade, agora em segundo plano, para o imaterial do pensamento. Embora Lucy Lippard tenha salientado a essência efêmera e barata da produção conceitual, sabe-se que nos anos 1960 e 1970 as ferramentas de reprodução de imagens não poderiam ser descritas como facilmente acessíveis aos jovens artistas de países periféricos como o Brasil (LIPPARD, 2001, p. VII).

Apesar da defasagem tecnológica, a arte brasileira do momento estava afinada à discussão travada no circuito internacional. Muitos dos jovens artistas locais que faziam arte de vanguarda radicalizaram suas poéticas rumo à desmaterialização conceitual, embora alguns deles não gostassem dessa alcunha, talvez devido ao dogmatismo pregado por Kosuth, expoente estadunidense da corrente. Ressalta-se que a tendência no Brasil não foi algo imposto de fora pelas potências internacionais, mas fenômeno 
que, sempre em diálogo com o que se passava no mundo, gerou-se internamente. A passagem da obra tradicional para o objeto e do objeto para a proposta/situação/ideia também ocorreu no país de forma natural: prova disso é a "nova objetividade" afirmada por Hélio Oiticica em textos de 1966 (OITICICA, 2006b, p. 147-148 passim) e 1967 (OITICICA, 2006a, p. 154-168 passim), para quem esta é a característica principal da vanguarda brasileira: a busca do objeto em detrimento das categorias tradicionais da pintura e da escultura. $\mathrm{O}$ relevo, contudo, não estaria no objeto como algo fechado e acabado, mas nas relações travadas entre e ele e o espectador. Oiticica incluía o espectador na obra, visto agora como um participante ativo e não mais observador contemplativo. Deslocava, assim, a arte para o campo da experiência por meio do objeto, sendo, portanto, um esforço rumo à desmaterialização, embora este conceito tenha sido proposto apenas em 1967, por Lippard e Chandler.

Dessa forma, a tendência à desmaterialização, com sua ênfase na ideia e/ou na ação, deu-se de forma simultânea no Brasil e no exterior, superando a tradicional defasagem da arte local em relação ao produzido nos Estados Unidos e na Europa. Essa origem interna permitiu à arte local, conquanto sempre em diálogo com a criação internacional, ter alto grau de autonomia e originalidade. Tanto no Brasil quanto em outros países da América Latina, a arte conceitual surgiu não apenas como uma tendência que problematizou o sentido e a função da arte, mas que também questionou o contexto social e político no qual estava inserida, conforme pensa Mari Carmen Ramírez (2007, p. 188). A pesquisadora salienta a heterogeneidade da arte conceitual latino-americana e questiona a noção redutora de que a tendência teria sido um modismo importado. Para ela, as obras elaboradas no continente não foram meras réplicas ou reflexo do que ocorria no mundo anglo-saxão, mas contribuições originais (RAMÍREZ, 2007, p. 186).

Conforme a autora, a arte conceitual latino-americana teria natureza ideológica, com forte crítica aos governos ditatoriais que oprimiam os países da região e denúncia das mazelas sociais ali presentes, de forma expandir a tautologia em direção à problematização das estruturas sociais e políticas (RAMÍREZ, 2007, p. 188). Freire igualmente destaca a contextualização e o ativismo político como peculiaridades da produção conceitual latino-americana em detrimento da autorreferencialidade da tendência estadunidense e europeia (FREIRE, 2006, p. 10). Como exemplo disso, Ramírez cita a exposição Tucumán Arde, ocorrida em 1968, nas cidades argentinas de Rosário e Buenos Aires, na qual os artistas denunciaram abertamente a exploração governamental sobre a província de Tucumán, marcada por uma situação de pobreza extrema. Os artistas picharam a capital da província com a expressão Tucumán Arde e, posteriormente, expuseram cartazes com dados a respeito da realidade opressiva vivida pela população local. A ideia dos artistas era criar um circuito informacional paralelo à grande mídia, que distorcia os fatos e era cúmplice do governo na exploração dos trabalhadores locais (GRAMUGLIO; ROSA, 1999, p. 77).

Além da aproximação entre arte e política, Ramírez também salienta outros dois aspectos como particularidades da produção regional em relação à estadunidense: a recuperação do objeto, especialmente, a noção duchampiana de readymade, que no contexto deste estudo se pensa não como fim, mas como meio para transmissão da ideia ou da experiência; e a utilização das teorias da informação, com recorrência aos meios massificados de comunicação (RAMÍREZ, 2007, p. 188). No seu pensar, a arte latino-americana, inclusive, antecipou questões que seriam tratadas pela arte conceitual internacional apenas depois de anos, como é o caso da vertente ideológica surgida nos Estados Unidos e na Europa a partir de meados da década de 1970, que discutiu temas como racismo e feminismo (RAMÍREZ, 1993, p. 156). De acordo com Blake Stimson, o ponto de virada da arte conceitual internacional se deu em meados dos anos 1970, com a expansão da crítica inicial às instituições artísticas, definidoras e agenciadoras dos papeis dos agentes da arte, em direção à crítica de um contexto social mais amplo, como ocorreu com o Group Material, um coletivo de artistas ativistas baseado em Nova York (STIMSON, 1999, p. XLV). 
Artistas da geração dos anos 1960, como o brasileiro Cildo Meireles, o argentino Victor Grippo e o uruguaio Luis Camnitzer, transformaram a condição de subdesenvolvimento de seus países em estratégia poética que lhes permitiu superar o conservadorismo do circuito local (RAMÍREZ, 1993, p. 157). Nesse sentido, criadores como Artur Barrio, fizeram uso de materiais precários, tomando uma posição em consonância com o caráter periférico da economia brasileira na época. Tais materiais, baratos e perecíveis, foram usados na confecção de uma arte efêmera como forma de contestação da elite e do poderio das potências internacionais (BARRIO, 2002a, p. 145). Estas tinham ao seu alcance itens tecnológicos. E o artista brasileiro, devido à sua condição periférica, não poderia fazer frente a eles se também recorresse à tecnologia, pois sempre estaria em atraso, no dizer de Frederico Morais (MORAIS, 1970, p. 59). Assim, a arte efêmera, feita com o uso de materiais pobres, colocar-se-ia como estratégia interessante de rompimento com essa estrutura hierárquica e, consequentemente, com a ideologia dominante da elite (BARRIO, 2002a, p. 145).

Frederico Morais, militante em prol da arte conceitual, vista por ele como vanguarda radical, defendeu o uso de materiais precários como uma forma de tomar posição diante da opressão propagada pelas potências mundiais por meio do uso da tecnologia. Deslocar o relevo do objeto para a ideia ou o processo seria então um modo de se opor à repressão imposta pela tecnologia (MORAIS, 1970, p. 57). Não só os materiais deveriam ser efêmeros, mesmo as ações dos artistas deveriam ser rápidas e inusitadas. Estes deveriam fazer arte-guerrilha, atuando como os guerrilheiros, de modo imprevisto e radical (MORAIS, 1970, p. 59). Produziriam obras inacabadas, que abarcassem a experiência do espectador como algo inerente à criação. Destarte, o público seria chamado à criação, compartilhando de igual status que o artista, o crítico e o curador. Haveria uma troca de funções entre os agentes da arte e todos poderiam se transformar em criadores (MORAIS, 1970, p. 50). Enfim, a arte passaria por um processo libertário e de democratização. Em consonância com a troca de papeis pelos agentes da arte proposta por Morais, na arte conceitual um grande número de artistas toma de empréstimo a função do crítico ao elaborar textos sobre sua própria obra, como foi o caso de Joseph Kosuth, de Sol LeWitt e do grupo Art\&Language, a que se recorreram para a realização deste estudo. Nesse sentido, vale destacar o boom de revistas sobre arte que traziam textos a respeito da produção conceitual, muitos dos quais escritos pelos próprios artistas. Como exemplo de periódicos que atuavam nessa frente citam-se Art-Language e The Fox, ambos publicados pelo grupo Art\&Language, que cresceu ao longo dos anos, reunindo dezenas de artistas conceituais, para além dos seus quatro fundadores. Outras revistas foram igualmente relevantes para a difusão e aumento de prestígio da arte conceitual, como a estadunidense Artforum, a alemã Interfunktionem, a suíça Art International e a britânica International Studio (ARCHER, 2008, p. 87).

É importante salientar que, embora alguns artistas brasileiros tenham recorrido ao uso de técnicas de reprodução, como a fotografia e o filme, para registrar suas obras e assim poder levá-las à instituição museológica e torná-las conhecidas pelo público, outros não tiveram essa oportunidade. Suas obras se perderam no tempo, o que os relegou à obscuridade, dificultando, inclusive, o trabalho de historiadores, que se esforçam para atribuir a relevância que tais artistas de fato merecem. Esse é o caso de Walkyria Proença, importante artista da época, ainda em atividade. A artista não possui registro de suas proposições dos anos 1960/70. Travou-se contato com uma de suas obras por meio do audiovisual de Frederico Morais $O$ pão e o sangue de cada um. Nele o crítico - aqui atuando como crítico-artista, em consonância com sua proposta de expansão das atividades do crítico rumo à criação - contrapôs imagens de obras de Barrio, elaboradas com detritos, com outdoors de propaganda de fast-food. Dialogando com a obra de Barrio, Morais faz uso de um dos raros registros de trabalho de Proença: um absorvente usado e jogado em um terreno baldio. A radicalidade do ato permaneceria relegado à memória dos que o presenciaram devido à falta de maior documentação, que comunicasse sua existência para o espectador. É importante salientar que, por outro lado, parte dos registros da produção conceitual, especialmente a internacional (apesar desta se tratar de uma arte que se propunha desmaterializada e contrária ao mercado), tornaram-se, anos depois, produtos de consumo. E a linguagem conceitual, por sua vez, transformou-se no modelo do establishment, face à 
institucionalização de tal tendência e o consequente embotamento de seu caráter inconformista (RAMÍREZ, 2007, p. 187).

A potência da arte conceitual produzida no Brasil era tão pulsante que chamou a atenção de Kynaston McShine, curador de Information. De passagem no Brasil em ocasião do Salão da Bússola importante evento ocorrido no Museu de Arte Moderna do Rio de Janeiro (MAM-RJ), em 1969, e que serviu de trampolim para a incipiente geração de artistas conceituais do país -, McShine convidou quatro artistas brasileiros a participar da exposição no MoMA: Hélio Oiticica, Cildo Meireles, Artur Barrio e Guilherme Vaz.

\section{Guilherme Vaz: desmaterialização e radicalidade}

Embora algumas das obras da época de Cildo Meireles e Artur Barrio tivessem forte viés político, em consonância com a teoria de Ramírez sobre a arte conceitual latino-americana, os trabalhos de Guilherme Vaz, ao contrário, se voltavam mais para o uso da linguagem escrita ou falada. Além de artista, Vaz é também músico e maestro, sendo, portanto, um criador multimídia. Compôs várias trilhas sonoras para filmes de diretores de vanguarda como Júlio Bressane, Ruy Guerra e Nelson Pereira dos Santos. Interessa aqui o período de sua carreira que engloba do final de 1960 a meados de 1970. Entre as exposições de que participou, destacam-se como as mais relevantes: o Salão da Bússola (1969), Agnus Dei (1970), Information (1970) e a VIII Bienal de Paris (1973) (MANATA, 2016, p. 11-12 passim).

O artista nasceu em Araguari, Minas Gerais, em 1948. Mudou-se com a família para Brasília em 1961. Estudou música na Universidade de Brasília e, depois da intervenção militar que fechou a instituição, na Universidade Federal da Bahia (MANATA, 2016, p. 15). Envolveu-se com música concreta, jazz, MPB e música arcaica (MANATA, 2016, p. 12). No final dos anos 1960, Vaz iniciou sua trajetória como artista conceitual. Segundo o criador, a arte como ideia, como coisa mental, surgiu no contexto brasileiro graças especialmente ao chamado "grupo de Brasília", formado por ele mesmo, Cildo Meireles, Luiz Alphonsus e Thereza Simões. Embora nenhum deles fosse natural do CentroOeste do país, eles tinham em comum a pesquisa linhada à desmaterialização da arte, o que, segundo Vaz, refletia os espaços vazios do Planalto Central (MANATA, 2016, p. 26).

É importante esclarecer que o grupo de Brasília não se tratava de um agrupamento formal de artistas alinhados a um movimento, como salienta Manata, mas conjunto de amigos com afinidades poéticas que emergiu com o Salão da Bússola, em 1969 (MANATA, 2016, p. 26). De acordo com Guilherme Vaz, Frederico Morais se destacou como o único crítico realmente importante para a legitimação do grupo (MANATA, 2016, p 27). De fato, Morais militou em nome da incipiente vanguarda conceitual brasileira, e abriu espaço para os jovens artistas ligados a ela nos eventos por ele organizados, debateu sobre suas obras, refletiu sobre as principais questões pertinentes à tendência e dialogou com seus artistas. Morais descreveu a proposição apresentada por Vaz em ocasião do Salão da Bússola:

Um outro artista, músico experimental, no mesmo salão, simplesmente comunicava aos visitantes (com o tácito apoio do júri, que considerou válida sua proposta) as experiências a serem feitas - fora do salão. Por exemplo, correr, em qualquer lugar, em espaço aberto ou fechado, verticalmente, em escadas, ou horizontalmente, nas praias, por quanto tempo desejar; ou permanecer em silêncio, em um grupo. A experiência termina com o cansaço do corredor ou com o primeiro barulho. $\mathrm{O}$ resultado não é a elaboração de uma determinada obra, mas um enriquecimento do indivíduo. Guilherme Vaz usou o salão (onde marcou com giz, no chão, uma área, 
colocando-se ali, ao lado de pequenos 'sinais') como veículo (MORAIS apud MANATA, 2016, p. 28-29 passim).

Vaz, ao convocar o espectador a participar de suas proposições, incluía-o na criação, democratizandoa. O público saía, assim, de sua passividade habitual, pois, na arte tradicional deveria contemplar a obra, ativando apenas o sentido da visão, e cultuá-la como algo distante, inalcançável. Quando o artista propõe ações como arte, qualquer um pode se tornar cocriador ao realizar o que foi demandado. Segundo Morais, o artista se transforma naquele que "puxa o gatilho": propõe uma experiência ao público (MORAIS, 1970, p. 50-51 passim). É este último, porém, quem se responsabiliza pelos desdobramentos da obra, a qual se realiza com e na experiência estética do espectador.

É na vivência que todos os sentidos do indivíduo e seu intelecto serão despertos e o espectador será libertado das amarras às quais ele normalmente se encontra subjugado pela opressão do sistema da arte, que o submete à uma posição de apatia e alienação. Isso porque no sistema tradicional da arte o espectador forma a base piramidal de sua estrutura, estando submetido à aura da arte e ao poder da palavra do artista, do crítico, do curador, do galerista. Contudo, se ele é chamado a partilhar da criação, adquire status semelhante ao desses personagens, pois se transforma em peça-chave no devir da arte: esta depende dele para sua existência. Da mesma forma, a obra passa a depender do espectador também para adquirir sentido. Ou seja, ao ser chamado à criação o espectador também participa na confecção da rede de significados que compõem a obra. Rede esta capaz de atualizar a obra, tornando-a sempre contemporânea e pertinente. Tal visão está de acordo com a ideia de Frederico Morais acima mencionada a respeito da mudança de papeis dos atores no interior do sistema da arte como estratégia da arte-guerrilha.

Ademais, a arte desmaterializada, exemplificada nas ações propostas por Vaz aos visitantes do Salão da Bússola, radicaliza a fusão entre arte e vida, uma aproximação iniciada no início da década de 1960, com tendências como a pop e o minimalismo. Com as propostas experimentalistas da arte conceitual a ênfase sai, cada vez mais, do objeto para a criação, não mais vista como um fenômeno dado de cima para baixo, mas como uma relação dialógica entre iguais, artista e espectador. A arte se aproxima da vida cotidiana do público, sai de sua autorreferencialidade própria à estética modernista para se converter em coisa contextualializada, não mais uma realidade apartada do cotidiano. Ela se transforma, assim, em uma forma refinada e intensa de experiência de vida (MORAIS, 1975, p. 61).

No mesmo ano de 1969, Vaz apresentou Sapatos Quentes, que consistiu em uma caminhada realizada pelo artista até o MAM-RJ. Depois, ele retirou sua camisa, a deu para um espectador e colocou seus sapatos em suas mãos, vestindo-os, o que, segundo depoimento do artista dado a Franz Manata, seria um "exercício filosófico sobre entrega e desapego" (VAZ apud MANATA, 2016, p. 29). A proposta do artista, mais uma vez, recaiu não sobre um objeto acabado, mas sobre a ação e a experiência vivida. Os objetos, como a camisa e os sapatos, ali existem não como obra, mas como vestígios que testemunham o ato estético. A ação do artista mais uma vez reafirma a diluição da arte na vida, tensionando esta última ao criar uma situação inusitada capaz de causar estranheza ao espectador.

Ainda em 1969, Vaz criou, ao lado de Frederico Morais, Cildo Meireles e Luiz Alphonsus, a Unidade Experimental do MAM-RJ, um laboratório de linguagem no dizer de Morais (1995, p. 310). Ela se direcionava à pesquisa artística não limitada às categorias tradicionais. Também se dirigia no sentido de agrupar possíveis colaboradores, contribuir com outros setores do museu e explorar a ludicidade de mulheres e homens. Entre as atividades da unidade, que funcionou por cerca de um ano, Morais destaca debates com artistas, teóricos e cientistas, um curso ministrado por Meireles, um concerto regido por Vaz, e uma pesquisa sobre o perfil dos visitantes do MAM-RJ (MORAIS, 1995, p. 310).

Já em 1970, por ocasião de sua exposição para a série Agnus Dei, na Petite Galerie, o artista propôs Ato de desapropriação de datas (área/tempo). Trata-se de instruções, derivadas de um trabalho do ano anterior feito em inglês, agora traduzidas para o português. No trabalho, o artista desapropriou 
datas aleatórias e as tornou obras. Na mesma mostra, Vaz escreveu um aviso no qual se apropriou de todos os visitantes da exposição (MANATA, 2016, p. 29). Nestas duas propostas o artista pareceu atribuir à realidade, como o espaço, o tempo e o ser humano, uma dimensão artística. Assim, ele retirou esses elementos da banalidade corriqueira e os transformou com seu ato em forças criativas, imersas no âmbito da arte.

É importante destacar que Vaz, em diálogo com a arte conceitual internacional, fez uso recorrente da palavra escrita na forma de instruções como estratégia. $\mathrm{O}$ artista usou como poética, muitas vezes, a palavra a ser transformada muitas vezes em ações, de modo a construir uma arte precária e efêmera, em consonância com a pobreza de materiais pregada por Morais e por artistas brasileiros como tática para lidar com a inacessibilidade dos artigos tecnológicos aos criadores locais. Além disso, a precariedade na obra de Guilherme Vaz também parece propor uma arte ancorada na riqueza e na multiplicidade da simplicidade: a potência da ideia não está necessariamente ligada à sua complexidade, podendo-se recorrer à economia de recursos, como também defende o conceitualista estadunidense Sol LeWitt (LEWITT, 2006a, p. 177). A palavra e a ação foram, assim, estratégias para a elaboração de uma arte desmaterializada, acessível ao artista e ancorada na experiência estética tanto deste quanto do espectador, chamado a realizar as instruções propostas por Vaz.

Para Information, seu curador, Kynaston McShine, convidou quatro artistas brasileiros: Hélio Oiticica, Cildo Meireles, o portuense radicado no Rio de Janeiro Artur Barrio e Guilherme Vaz, como já mencionado. Embora Vaz não tenha participado com obra no espaço museológico, pois perdeu o prazo para envio do trabalho, publicou no catálogo da mostra uma fotografia apropriada de jornal com a imagem de indígenas (GUILHERME VAZ: UMA FRAÇÃO DO INFINITO, 2016, p. 206). Com o recurso à apropriação, o artista questionava a noção de autoria, ampliando-a. O criador da obra deixa então de ser somente quem a cria no sentido tradicional do termo e passa a ser também quem a escolhe, pois a escolha é também ela um ato de criação.

Entre as instruções de Vaz elaboradas no período em estudo, estão "Ande para qualquer lugar, durante qualquer tempo, por qualquer distância, de qualquer maneira" e "Caminhe nesta área, sinta o calor dos próximos passos", cuja concepção se deu em 1970. Foram, porém, gravadas em fita cassete em 1974. Esses trabalhos eram também chamados pelo artista de música conceitual ou música corporal (GUILHERME VAZ: UMA FRAÇÃO DO INFINITO, 2016, p. 150). A voz do artista era usada como estratégia desmaterializada que poderia se reverberar na também desmaterializada ação do espectador que se empenhasse em seguir suas proposições. Assim, não se pode ver tais instruções como obras completas, fechadas, posto que necessitam da adesão do espectador-participante para se desdobrarem e se transformarem em experiência estética.

No trabalho Cru, elaborado para a VIII Bienal de Paris, em 1973, o artista interagiu com a arquitetura da instituição expositora de modo a tirar sons de sua parede, numa proposta multimídia que congregou música e performance, contribuindo para a dissolução entre as fronteiras das diferentes linguagens artísticas (GUILHERME VAZ: UMA FRAÇÃO DO INFINITO, 2016, p. 151). Ademais, Vaz ressaltou a existência do espaço expositivo, geralmente tornado invisível na concepção tradicional de arte. $\mathrm{Na}$ instituição museológica convencional é requerido aos seus frequentadores uma postura de submissão e passividade. Ela se coloca como templo destinado ao culto de obras de arte (O’DOHERTY, 2002). No entanto, ao interagir com a parede, o artista rompe com o caráter sagrado do museu tradicional e destaca sua presença como elemento vivo que dialoga diretamente com o trabalho artístico.

Killed se tratou de um projeto de obra feito à caneta sobre papel em 1970 e finalmente realizado em 2015. A proposta contava apenas com a palavra inglesa killed escrita sobre uma superfície retangular (GUILHERME VAZ: UMA FRAÇÃO DO INFINITO, 2016, p. 160). Em consonância com a vertente internacional da arte como ideia, Vaz fez uso da palavra escrita para acionar a participação mental do espectador. Este é instigado pelo artista a refletir sobre os possíveis significados da obra, de modo a tensionar sua percepção da arte. Já em uma obra sem título, de 1975, o artista elaborou um 
inventário, listando os trabalhos que realizou ao longo de seus 10 anos de carreira, entre as quais figuravam instruções que recorriam ao uso da linguagem escrita ou falada, apropriações e composições musicais (GUILHERME VAZ: UMA FRAÇÃO DO INFINITO, 2016, p. 166). A página, que poderia ser um item de arquivo devido ao seu caráter informacional e nada emotivo, é agora problematizada como arte.

Em meados dos anos 1970, Vaz se decepcionou com a arte conceitual, a qual para ele havia se tornado formalista, e decidiu fazer incursões no Centro-Oeste e no Norte brasileiro, em busca da sonoridade do Brasil profundo, num movimento de pesquisa antropológica e musical (MANATA, 2016, p. 52). Sua apropriação de foto de tribo ameríndia publicada no catálogo de Information já apontava esse futuro redirecionamento para a mata e para o sertão. Esse movimento significou um afastamento proposital do circuito artístico, o que acabou por relegar a obra desse notável artista à certa obscuridade.

\section{Considerações finais}

Promotor de uma poética original, Guilherme Vaz foi um expoente da arte conceitual no Brasil concomitantemente ao aparecimento da tendência nos países centrais do globo. $\mathrm{O}$ criador soube dialogar com tal vertente, sendo um exemplo de artista que articulou o local com o universal, realizando uma arte que despertou interesse no Brasil e no exterior, o que sua participação em mostras como Information e a VIII Bienal de Paris comprovam. Vaz fez uso da linguagem como estratégia radical de criação desmaterializada, como pode ser visto na profusão de documentos e projetos de obras não realizados no mesmo período de sua concepção, sendo concretizados apenas recentemente, como é o caso de Killed (1970-2015). Como os membros do Fluxus, grupo que reuniu vários artistas performáticos de diversos países bem no início dos anos 1960, ele propôs instruções escritas ou faladas como arte, convocando o espectador à realização das ações sugeridas e, assim, à participação no processo criativo.

Enfim, esta pesquisa buscou esclarecer as principais questões que permearam a arte conceitual não apenas no âmbito estadunidense, mas também no brasileiro, destacando o diálogo entre ambas, as semelhanças e peculiaridades locais. Para uma maior elucidação sobre a tendência, usou-se como exemplo a poética de Guilherme Vaz, expoente brasileiro, que contribuiu para o debate em torno da produção conceitual com uma obra complexa em sua simplicidade, desmaterializada, democrática e profundamente radical.

\section{Referências}

ARCHER, Michael. Arte contemporânea: uma história concisa. São Paulo: Martins Fontes, 2008.

ART\&LANGUAGE. Arte-linguagem. In: FERREIRA, Glória; COTRIM, Cecília. Escritos de artistas: anos 60/70. Rio de Janeiro: Jorge Zahar, 2006, 235-248.

BARRIO, Artur. Manifesto. In: CANONGIA, Ligia (Org.). Artur Barrio. Rio de Janeiro: Modo, 2002a, p. 145. $\overline{\text { p. } 148-149 \text {. }}$

. Manifesto contra do júri. In: CANONGIA, Ligia. Artur Barrio. Rio de Janeiro: Modo, 2002b,

BUCHLOH, Benjamin. Conceptual art 1962-1969: from the aesthetic of administration to the critique of institutuions. In: ALBERRO, Alexander; STIMSON, Blake (Orgs.). Conceptual art: a critical anthology. Cambridge, London: MIT Press, 1999, p. 514-537.

FERREIRA, Glória; COTRIM, Cecília. Apresentação. In: debate crítico. Rio de Janeiro: Jorge Zahar, 2001. p. 13-25.

(Orgs.). Clement Greenberg e o 
FREIRE, Cristina. Arte conceitual. Rio de Janeiro: Jorge Zahar, 2006.

GRAMUGLIO, María Teresa; ROSA, Nicolás. Tucumán Burns. In: ALBERRO, Alexander; STIMSON, Blake (Orgs.). Conceptual art: a critical anthology. Cambridge, London: MIT Press, 1999, p. 76-79.

GREENBERG, Clement. Rumo a um mais novo Laocoonte. In: FERREIRA, Glória; COTRIM, Cecília (Orgs.). Clement Greenberg e o debate crítico. Rio de Janeiro: Jorge Zahar, 2001, p. 45-59.

GUILHERME VAZ: UMA FRAÇÃO DO INFINITO. Rio de Janeiro: EXST, 2016, 320 p. Catálogo de exposição.

INFORMATION. Nova York: MoMA, 1970. Catálogo de exposição.

KOSUTH, Joseph. A arte depois da filosofia. In: FERREIRA, Glória; COTRIM, Cecília. Escritos de artistas: anos 60/70. Rio de Janeiro: Jorge Zahar, 2006, p. 210-234.

LEWITT, Sol. Parágrafos sobre arte conceitual. In: FERREIRA, Glória; COTRIM, Cecília. Escritos de artistas: anos 60/70. Rio de Janeiro: Jorge Zahar, 2006a, p. 176-181.

. Sentenças sobre arte conceitual. In: FERREIRA, Glória; COTRIM, Cecília. Escritos de artistas: anos 60/70. Rio de Janeiro: Jorge Zahar, 2006b, p. 205-207.

LIPPARD, Lucy; CHANDLER, John. The dematerialization of art. In : ALBERRO, Alexander; STIMSON, Blake (Orgs.). Conceptual art: a critical anthology. Cambridge, London: MIT Press, 1999, p. 46-50.

. Six years: the dematerialization of the art object from 1966 to 1972. Berkeley: University of California Press, 2001.

MANATA, Franz. O vento sem mestre. In: GUILHERME VAZ: UMA FRAÇÃO DO INFINITO. Rio de Janeiro: EXST, 2016, p. 11-61. 320 p. Catálogo de exposição.

MORAIS, Frederico. Artes plásticas: a crise da hora atual. Rio de Janeiro: Paz e Terra, 1975.

. Contra a arte afluente: o corpo é o motor da obra. Revista de Cultura Vozes, Rio de Janeiro, ano 64, v. 64, n. 1, p. 45-59, jan./fev. 1970.

. Cronologia das artes plásticas no Rio de Janeiro. Rio de Janeiro: Topbooks, 1995.

. Pequena história da arte moderna e contemporânea: do objeto ao conceito. Rio de Janeiro: Soraia Cals, 2007, 2007, 335 p. Catálogo de leilão. Não paginado.

O’DOHERTY, Brian. No interior do cubo branco: a ideologia do espaço na arte. São Paulo: Martins Fontes, 2002.

OITICICA, Hélio. Esquema geral da nova objetividade. In: FERREIRA, Glória; COTRIM, Cecília (Orgs.). Escritos de artistas: anos 60/70, Rio de Janeiro, Jorge Zahar, 2006a, p. 154-168.

. Situação da vanguarda no Brasil. In: FERREIRA, Glória (Org.). Crítica de arte no Brasil: temáticas contemporâneas, Rio de Janeiro: Funarte, 2006b, p. 147-148.

PEDROSA, Mário. Arte ambiental, arte pós-moderna, Hélio Oiticica. In: FERREIRA, Glória (Org.). Crítica de arte no Brasil: temáticas contemporâneas, Rio de Janeiro: Funarte, 2006, p. 143-145.

RAMÍREZ, Mari Carmen. Blue print circuits : conceptual art and politcs in Latin America. In: RASMUSSEM, Aldo (Org.). Latin american artists of the twentieth century. New York: MoMA, 1993, p. 156-169. Catálogo de exposição.

. Táticas pra viver da adversidade: o conceitualismo na América Latina. Arte\&Ensaios. Rio de Janeiro, ano 14, n. 15, p. 185-195, 2007. 
STIMSON, Blake. The promise of conceptual art. . In: ALBERRO, Alexander; (Orgs.). Conceptual art: a critical anthology. Cambridge, London: MIT Press, 1999, p. XXXVIII-LII. WOOD, Paul. Arte conceitual. São Paulo: Cosac Naify, 2002. 